ISSN 1518-3483

Licenciado sob uma Licença Creative Commons

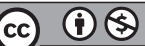

\title{
Educação e complexidade: possibilidade de uma relação mais orgânica
}

\author{
Education and complexity: possibility of \\ a relation more organic
}

\section{José Augusto Florentino ${ }^{[a]}$, Cleoni Maria Barboza Fernandes ${ }^{[b]}$}

[a] Professor da Escola Factum Ensino Técnico, Mestre em Ciências Sociais e Doutorando em Educação do Programa de Pós-Graduação em Educação da Faculdade de Educação da Pontifícia Universidade Católica do Rio Grande do Sul (PUCRS), Porto Alegre, RS, Brasil, e-mail: jose.a.florentino@gmail.com

[b] Professora pesquisadora do Programa de Pós-Graduação em Educação da Faculdade de Educação da Pontifícia Universidade Católica do Rio Grande do Sul (PUCRS), Porto Alegre, RS, Brasil, e-mail: cleoni.fernandes@pucrs.br

Não se pode imaginar um futuro para a humanidade sem educadores. (GADOTTI, 2003, p. 17)

\section{Resumo}

O presente artigo é uma reflexão conjunta entre dois professores - doutorando e orientadora - com o intuito de discutir o paradigma da complexidade e suas possibilidades para a educação de um ser humano melhor. Complexo e necessário exercício acadêmico e de humana experiência dialógica. Para tanto, o objetivo é o de discutirmos abordagens de 
como trabalhar com o humano, o social e, sobretudo, com o pedagógico, na tentativa de resgatar a produção de sentido entre aprender e ensinar. Não obstante, estamos diante de uma sociedade caracterizada pelo pluralismo de ideias e pela complexidade das práticas sociais e dos saberes nela e com ela produzidos. Dessa forma, é de suma importância que nós professores nos apercebamos de que é preciso haver a mudança do olhar e do sentir. Em suma, para uma educação de presente-futuro ético e de humanas gentes é necessário investir no desenvolvimento de ser humano em sua multidimensionalidade pessoal, cultural e profissional, em que a humanidade de suas ações tenha a capacidade de promover a solidariedade, a prática social e cidadã.

Palavras-chave: Paradigma da complexidade. Formação docente. Prática pedagógica.

\section{Abstract}

This article is a joint discussion between two teachers - a PhD student and supervisor - in order to discuss the paradigm of complexity and its possibilities for the education of a better human being. Complex and necessary exercise of human experience and academic dialogue. Thus, the goal is to discuss approaches to working with the human, social and particularly with the teaching, trying to rescue the production of meaning between learning and teaching. Nevertheless, we face a society characterized by pluralism of ideas and the complexity of social practices and knowledge with her and she produced. Thus, it is critical that we teachers in noticing that there must be a change of look and feel. In summary, for an education in present-future ethical and human nations need to invest in developing human being in its multidimensionality personal, cultural and professional, where the humanity of their actions have the capacity to promote solidarity, social practice and citizen.

Keywords: Complexity. Teacher training. Pedagogical practice.

\section{Introdução}

Este texto apresenta uma reflexão conjunta entre dois professores diante de um trabalho de tese em elaboração - doutorando e orientadora. 
De uma sessão de orientação, surgiu a provocação de escrever juntos: proposta do doutorando para discutir um tema empolgante, da moda, às vezes tão banalizado. Sem a pretensão de esgotamento da temática ou da discussão conjunta, as vozes de autorias de diferentes lugares foram resgatadas para esse encontro de gentes e de referenciais, respeitados o estilo e a base teórica de cada um. Complexo e necessário exercício acadêmico e de humana experiência dialógica.

Não obstante, são indeléveis os eixos de mudanças e transformações de toda a ordem - econômica, política, social, educacional, cultural e ambiental - que têm caracterizado as sociedades ao longo do século XX e nessa primeira década de terceiro milênio.

No passado a sociedade estava assentada na estabilidade, na regularidade, na previsibilidade, em um paradigma linear, reducionista, não complexo. A reprodução do passado dominava o projeto da sociedade e seus princípios eram modelos que deveriam ser seguidos, reproduzidos. Por outro lado, na sociedade contemporânea, com a transição paradigmática (SOUSA SANTOS, 1987) que estamos vivendo, os modelos de produção do conhecimento e da vida são colocados em dúvida, não havendo mais um estatuto científico sociocultural de verdades perenes, irrefragáveis.

Inserimo-nos, assim, no debate que tem ocorrido, por diferentes pensadores, em diversos campos do conhecimento, qual seja, o "novo paradigma científico”. Esse pensamento novo-paradigmático dito por Vasconcellos (2005) ou paradigma emergente, como descreve Sousa Santos (1987) - entendido do ponto de vista epistemológico como aumento de complexidade - está marcado pela perda das certezas, pelo indeterminismo e pela contingência.

O impacto epistemológico dessa verdadeira "revolução" na Ciência influenciou diferentes áreas do conhecimento - Física, Biologia, Psicologia, Sociologia -, sobretudo a Ciência da Educação. Tais áreas, cada uma à sua maneira, têm tratado a questão da complexidade de forma diferente, mas todas convergem no sentido de corroborar o surgimento de um novo arcabouço conceitual com vista a dar conta de um mundo e de uma educação que se têm mostrado cada vez mais complexos e dinâmicos. 
Assim, o presente artigo tem por objetivo pontuar e discutir o paradigma da complexidade e suas possibilidades para a educação de um ser humano melhor. O desafio que se coloca, então, é o de discutirmos abordagens de como trabalhar com o humano, o social e o epistemológico, sobretudo com o pedagógico, no intuito de resgatar a produção de sentido, ${ }^{1}$ por assim dizer, entre aprender e ensinar.

\section{Por que complexidade...}

A tradição cultural do pensamento hegemônico denominado de paradigma dominante instaurou-se, com a chamada Revolução Científica, a partir do século XVI com o filósofo René Descartes e, posteriormente, com o físico e matemático Isaac Newton, no século XVII; consolidando toda uma forma de pensar e fazer o conhecimento, tendo por base uma única racionalidade, uma única racionalização cognitiva instrumental, também denominada racionalidade técnica, aqui compreendida na lógica do racionalismo cartesiano e no empirismo baconiano, corporificada no positivismo oitocentista, em que "só há duas formas de conhecimento científico - as disciplinas formais da lógica e da matemática e as ciências empíricas segundo o modelo mecanicista das ciências naturais" (SOUSA SANTOS, 1987, p. 18-19).

Descartes acreditava na possibilidade de conhecer e de chegar a verdades absolutas a partir do uso da razão. Para isso, sistematizou toda uma nova ordem que buscava controlar a natureza e as forças do universo. De acordo com Fernandes (2001, p. 178), "era necessário, naquele momento, subjugar a natureza para atender às exigências do modo de produção capitalista em expansão. Essa visão vai determinar uma nova relação da humanidade com a natureza".

1 O termo sentido, neste texto, está fundado na ideia de Marilena Chauí: "o mundo suscita sentidos e palavras, as significações levam à criação de novas expressões linguísticas, a linguagem cria novos sentidos e interpreta o mundo de maneiras novas" (CHAUÍ, 1998, p. 149). 
A natureza, portanto, funcionava de acordo com leis mecânicas e tudo no mundo podia ser explicado em função da organização e por meio da análise de suas partes. Para Descartes, quando o fenômeno se encontra complexo, devemos "dividir cada uma das dificuldades [...] em tantas parcelas quantas necessárias fossem para melhor resolvê-la" (DESCARTES, 1997, p. 37-38).

O conhecimento científico foi por muito tempo - e com frequência ainda continua sendo - concebido como tendo por missão dissipar a aparente complexidade dos fenômenos a fim de revelar a ordem mais simples a que eles obedecem. No paradigma cartesiano-mecanicista a natureza tem uma ordem dada e sua estrutura para ser decifrada tem que ser fragmentada, disjuntada em pedaços, cada vez mais simples, para que possam ser medidos em toda a sua espessura, por menor que seja.

Assim, o racionalismo cartesiano independe dos objetos, estabelecendo, desse modo, um método único para a compreensão destes. Tal é o princípio da simplificação, da fragmentação, em que a prática pedagógica, ${ }^{2}$ uma vez alicerçada sob esses fundamentos, tendeu a organizar-se em uma visão de mundo - comumente chamada de cartesiana - assentada no velho princípio que busca simplificar, reduzir todo o problema em tantas partes quanto forem possíveis sem poder comunicar aquilo que está junto, isto é, sem poder entender o todo, o contexto ou a complexidade dos fenômenos de nossa sociedade e, por conseguinte, de nossa educação.

Sua concepção de natureza estava assentada em dois domínios independentes, quais sejam: o domínio da mente e o domínio da matéria. A esse respeito Fernandes (2001, p. 178-179, grifo nosso) salienta:

é a redução da riqueza da complexidade, das circularidades, que ficam aprisionadas em modelos e proposições como verdades absolutas, em que

2 Contrapomo-nos a esta visão e a concebemos como: "prática intencional de ensino e de aprendizagem, não reduzida à questão didática ou às metodologias de estudar e aprender, mas articulada a uma educação como prática social e ao conhecimento como produção histórica e cultural, datado e situado, numa relação dialética e tensionada entre prática-teoria-prática, conteúdo-forma, sujeitos-saberes-experiências e perspectivas interdisciplinares" (FERNANDES et al., 2003, p. 376, grifo nosso). 
a precisão da medição é o critério da própria verdade, sem as arquiteturas dos desejos, das emoções e das intuições, outras racionalidades que precisam compor e interagir na construção da professoralidade.

Isso porque, segundo a própria autora, as concepções de conhecimento que foram sendo formadas com o pensamento cartesiano excluíam os vínculos com o "mundo sensível” e com sua dimensão qualitativa das relações com o conhecimento da natureza física e humana. Tais relações foram substituídas por uma relação de exploração, o que acabou por configurar na fragmentação do ser humano em corpo, alma e intelecto.

Outrossim, vejamos, por exemplo, o modo como foi sendo construída a visão de corpo do ser humano ao longo da história. Visão essa que teve e, por que não dizer, ainda tem forte influência na maneira como pensamos e vemos a prática educativa.

O trato com o corpo do ser humano ao longo da história ocidental, alicerçado na ciência moderna [...] foi sendo construído a partir da ideia de homem-máquina, aquele que poderia ser manipulado, adestrado, disciplinado, em última análise, para o aparecimento de um corpo dócil, cumpridor de ordens, visando à manutenção do já estabelecido e da permanência do poder e dos poderosos (MOREIRA; PELLEGRINOTTI; BORIN, 2006, p. 186, grifo nosso).

O corpo humano, ao ser comparado com uma máquina, recebe uma educação que o considera apenas em seu aspecto mecânico, sem vontade própria, desprovido de desejos e sem o reconhecimento da intencionalidade do movimento humano, o que é explicado por meio da mera reação a estímulos externos, sem qualquer relação com a subjetividade.

O pensamento de Descartes, fundado no exercício do controle e no domínio da natureza, influenciou a educação por meio da racionalização das práticas corporais. Tal fato resulta no que vemos atualmente em nossa educação, um distanciamento entre a aprendizagem e as possibilidades de experiências sensíveis com relação a sua prática, fato esse explicado 
pelo desejo de querer um mundo durável de uma razão e racionalização que quantifica, mede e que considera os sentidos como enganadores. É assim, relata Gaya (2006), de modo hegemônico - centrado na racionalização - que se ensina na maioria de nossas escolas.

Consideramos que nessa argumentação está a relevância desta reflexão. Um espaço de questionamento que conduza a uma mudança de atitude, que substitua o pensamento do paradigma dominante (SOUSA SANTOS, 1987), no qual o professor é o transmissor de um saber especializado, por uma pedagogia mais complexa, em que professor e aluno partilham experiências, descubram potencialidades e se abram para um mundo plural e mutável.

Não obstante, Freire (1996, p. 23) destaca a importância dessa relação professor /aluno ao afirmar que: "quem ensina aprende ao ensinar e quem aprende ensina ao aprender”. E, assim, compartilhem juntos novas possibilidades de produção e construção de saberes, proporcionando um ao outro o diálogo e a interação.

Dentro desse panorama estabelecido, o mais importante enquanto educador é construir competências de humana docência (ARROYO, 2000); aprendendo a trabalhar com ferramentas tecnológicas cotidianas que nos auxiliem a enfrentar as contingências, a imprevisibilidade nas relações pedagógicas - relação humana entre professores e alunos mediada pelo trabalho com o conhecimento em seus meios de produção, disseminação e ressignificação na sala de aula (FERNANDES, 2003).

Poder-se-ia perguntar até que ponto nós professores e professores em formação estamos realmente nos preparando/preparados para lidar com o novo, com o imprevisível, com a complexidade. Ou, ainda, se estamos preparados para formar seres humanos capazes de expandirem suas habilidades e competências, em uma sociedade que se encontra cada vez mais distanciada de referenciais de valores de solidariedade, de projeto coletivo e de humana formação na perspectiva de uma antropologia reflexiva (VIEIRA PINTO, 1969), o que implica negação do modelo predeterminado da cultura, e sim produção da tecitura de relações da vida com o mundo da vida e do trabalho. 
Todos (gestores, escola, diretores, professores, pais e alunos), sem exceção, precisam estar comprometidos com a mudança na maneira de ver e sentir a nossa realidade. Trocmé-Fabre (2003) ressalta que todos os sistemas vivos (seres vivos) são complexos; a complexidade para a autora seria tudo aquilo que caracteriza a vida, isto é, a sua diversidade. Ela (complexidade) corresponde à multiplicidade, ao entrelaçamento, à continua interação entre as infinidades de sistemas e fenômenos que compõem o mundo natural (LIMA, 2006), e o mundo produzido pelas relações de produção desse próprio mundo do qual fazemos parte.

Entretanto, ainda hoje, em nossa experiência, percebemos que um dos grandes problemas para o trabalho com o paradigma complexo na educação está no não entendimento do que vem a ser realmente complexidade. Para Trocmé-Fabre (2003, p. 134), o grande empecilho para que a complexidade seja bem aceita na prática educativa se deve à tendência de confundir complexidade com complicação. Tal fato, salienta a autora, resulta em

práticas, ainda em voga, que consistem em decompor em elementos simples os componentes de uma estrutura ou de um sistema, e depois isolá-los para analisá-los [...] esta abordagem que ignora a função do contexto, a história das inter-relações e interdependências da estrutura com o seu meio ambiente (e com ela própria!), engaja-se num processo linear, compartimentado e compartimentador, que obscurece consideravelmente os processos de percepção, memorização, atenção e concentração, indispensáveis para estimular o interesse, a motivação, o engajamento na ação e a responsabilização daquele que aprende (TROCMÉ-FABRE, 2003, p. 134).

Assim, uma pergunta se faz necessária: será complexo tudo aquilo que consideramos ser complicado? Para responder a essa pergunta façamos uso de Morin e Le Moigne (2000), que salientam que a complexidade desafia, não dá respostas. É preciso pensar por meio da complicação, por meio das contradições. A ideia de complexidade comporta imperfeição, incerteza e o reconhecimento do irredutível. Independentemente 
das definições propostas a respeito da complexidade, ela surpreende pela irreversibilidade de seu conteúdo, por sua dificuldade de entendimento, por não possuir um sentido concreto. Com efeito, "difere da complicação, com a qual ela é confundida, por preguiça intelectual ou por galanteria retórica" (MORIN; LE MOIGNE, 2000, p. 219).

A complexidade, portanto, está presente naqueles momentos em que nem sempre é possível superar contradições, vencer obstáculos, antagonismos, ultrapassar os paradoxos porque as inter-relações e conexões estão tecidas juntas. Como bem podemos observar na prática pedagógica, em que desafios são impostos diariamente ao professor que necessita "dar conta" de superá-los - havendo nesse momento uma grande lacuna entre a teoria e a prática, pois em muitas situações ele (professor) não aprendeu a lidar/tratar com as contingências da sala de aula porque não as viveu reflexivamente na tecitura das relações pedagógicas.

Desse modo, a complexidade configura-se numa nova visão de mundo, que aceita e procura compreender as mudanças constantes do real e não pretende negar (é importante que digamos isso!) a multiplicidade, a aleatoriedade e a incerteza dos fenômenos, mas sim conviver com elas. Esse pensamento procura explicar os fenômenos considerando o seu contexto, a sua totalidade e a sua interatividade (FLORENTINO, 2007).

Tal fato é frequentemente esquecido na educação, principalmente no momento em que são propostas atividades fora de contexto, sem referências à realidade dos alunos, sem objetivo aparente a não ser responder ao professor, terminar os exercícios ou dar continuidade ao conteúdo programático. Devemos ter em mente que toda a aprendizagem precisa estar fundamentada, embasada, ancorada (COSTA, 2003, TRÓCME-FABRE, 2003) em práticas sociais contextualizadas, tanto no vivido quanto no por viver (FERNANDES, 1999).

Nessa concepção, o professor precisa perceber a complexidade não como um conceito teórico, mas como um fenômeno da vida e de sua prática pedagógica. O paradigma da complexidade surge em decorrência dos avanços do conhecimento e dos desafios impostos por uma sociedade da informação. Sua matriz epistemológica contrapõe-se aos princípios 
cartesianos da fragmentação do conhecimento, propondo outra forma de pensar e ver a realidade em que estamos inseridos.

Não obstante, a fragmentação do conhecimento, que se generaliza e se reproduz por meio da organização social e educacional, configura também o modo de pensar e agir de muitos professores (SANTOS, 2008).

De maneira sucinta, o pensamento complexo nada mais é que um pensamento plural, que lida com a ordem e a desordem, com a interação e a organização, tendo por característica principal a "religação, que visa reabrir as fronteiras entre as disciplinas do conhecimento e promover a intercomunicação entre os compartimentos estanques do saber, produzidos pelo pensamento fragmentador" (MARIOTTI, 2000, p. 88-89, grifo nosso).

Por isso, acreditamos que o professor - ao (re)conhecer o pensamento complexo e a própria complexidade do ato de aprender - pode experienciar processos pedagógicos que o auxiliem a responder às demandas, às expectativas, à diversidade e à riqueza de possibilidades dentro e fora da sala de aula.

Abrir-se para o paradigma complexo é uma condição necessária para que o ato de ensinar/aprender seja duradouro, rejeitando, desse modo, a busca incessante do rendimento, do desempenho, da quantificação. E isso só será possível se mudarmos nossa forma de agir e pensar, ou seja, se fizermos uso de uma epistemologia - e, por que não dizer, uma pedagogia - mais complexa. ${ }^{3}$

Pensamos que o professor, ao desenvolver uma abordagem mais complexa, estará oportunizando novas experiências, criando condições para que a educação se assuma como um valor de referência para seus alunos. Ou, como tão bem salienta Bento (2004, p. 35):

3 Para Morin, uma epistemologia complexa é a não mais existência de uma instância soberana, isto é, não há mais espaço para verdades absolutas, indubitáveis. $E$ isso vale também para a prática educativa! Ninguém, na opinião de Morin, é detentor de um saber verdadeiro. "Não existe trono soberano, mas uma pluralidade de instâncias" (MORIN; LE MOIGNE, 2000, p. 68). 
estou a pensar em tudo quanto nos perfaz por dentro e por fora, nos pensamentos e atos, nos sentimentos e gestos, nos ideais e nas palavras, nas emoções e reações. Estou a pensar no Homem-Todo, na pessoa de fora e na expressão da sua beleza e grandeza na pessoa de dentro.

\section{Ensinar e aprender na complexidade}

Reconhecer a complexidade do ato de aprender é imprescindível. Já que para uma educação emancipatória (FREIRE, 1987, 1996) é preciso que o professor e o professor em formação se abram para uma nova perspectiva, ou melhor, outro olhar de compreensão do mundo e das relações nele e com ele produzidas, qual seja: da complexidade, como pontuamos ao longo desta reflexão.

Ensinar e aprender são atos inseparáveis. O ser humano desde o seu nascimento se encontra permanentemente aprendendo, encontra-se "inacabado", o que para Costa (2003, p. 267) significa uma

situação privilegiada para fazer emergir a complexidade [...] pois é na rede de relações dinâmicas ligando os sujeitos e os objetos de aprendizagem que se articulam o saber, a experiência vivida, a emoção, o desejo, o projeto, abrindo-se à possibilidade e ao questionamento, que vem substituir a evidência e a certeza.

O problema, no entanto, é transformar a complexidade em um corpo teórico que possibilite o diálogo com o conhecimento, o que pode representar um instrumento de reflexão, para todos nós professores, que permita compreendermos o sistema educativo como mudança, isto é, "como processo continuado de inovação, tal como demanda uma sociedade tecnológica, assentada sobre mesmos processos de mudança e que solicita da escola que tenha a mesma capacidade de formação para a mudança" (COLOM, 2004, p. 149, grifo nosso).

É necessário, portanto, ao tratar da prática pedagógica, que o professor escolha uma proposta que contemple a complexidade dessas 
práticas e de suas finalidades, as quais poderão incorporar subjetividades, singularidades - isto é, as interações - com as quais são vivenciados os processos de ensino-aprendizagem na sala de aula. Processos esses que se assentam sobre o inacabado, sobre a imaturidade do próprio educando (COLOM, 2004). É um processo progressivo que tem por objetivo fazer com que "os alunos dialoguem com os conhecimentos, reestruturando-se e retendo [cognitivamente] o que é significativo" (SANTOS, 2008, p. 81, grifo nosso), sendo uma construção pessoal, reflexiva e contextual.

Não obstante, nosso aluno não é mais o mesmo, ao ser o interlocutor das necessidades e transformações de nossa sociedade. Sendo assim, como professores, precisamos tentar compreender as suas demandas. Para isso, "é preciso escutá-lo [aluno], conhecer suas expectativas, abrir o diálogo entre os parceiros da situação educativa [...] para reconhecer na diversidade de respostas a riqueza de possibilidades, evitando julgamentos binários, irredutíveis, definitivos" (COSTA, 2003, p. 268-269, grifo nosso).

O papel de professor é o de instrumentalizar/potencializar o aluno, ajudando-o a desenvolver as suas capacidades, sempre respeitando a sua história, seu contexto, a sua cultura e suas experiências de vida (FREIRE, 1996), favorecendo espaço para a afetividade, a emoção, a alegria e a interação entre o coletivo da escola, fazendo emergir sentidos a partir das inter-relações que surgem entre o mundo em que vivemos, o conhecimento que produzimos, o professor e o aluno (COSTA, 2003).

Com efeito, ao educar para complexidade,

nós, educadores, precisamos ter clareza do que é aprender, do que é 'aprender a aprender', para entendermos melhor o ato de ensinar. Para nós educadores, não basta saber como se constrói o conhecimento. Nós precisamos dominar outros saberes da nossa difícil tarefa de ensinar. Precisamos saber o que é ensinar, o que é aprender e, sobretudo, como aprender (GADOTTI, 2003, p. 48).

Como nos diz Gadotti, precisamos aprender que educação e complexidade não podem mais serem tratadas de forma separadas. 
Precisam ser trabalhadas em conjunto, na tentativa de construir novos horizontes, novos conteúdos, novas práticas educativas, enfim, uma educação coerente com a nossa complexa realidade, assentada em objetivos plurais, enaltecendo o fortalecimento da ética do ser humano, da mobilização para a transformação e o cuidado com a vida.

\section{Uma educação de possibilidades para um ser humano melhor}

Vivemos nesta sociedade mutável que, cada vez mais, vai exigir professores que estejam preparados para enfrentar o instável, o desconhecido e, também, profissionais que formem cidadãos criativos, autônomos, que saibam lidar com o novo, que tenham espírito de liderança, que tenham responsabilidade e ética, que sejam solidários, que sejam sensíveis e afetuosos. E, para que isso ocorra, é preciso haver uma mudança na concepção de formação profissional do professor.

Como sabemos, o papel do professor mudou, antes ele era visto como um transmissor de conhecimentos, agora são necessárias muitas outras habilidades, tais como, "a capacidade de estimular o interesse por aprender [...] o cuidado com o desenvolvimento afetivo e moral, a atenção à diversidade dos alunos, a gestão da aula e o trabalho em equipe" (MARCHESI, 2006, p. 112), sem as quais fica difícil conseguir com que os alunos progridam na aquisição de um saber.

Caminhando nessa mesma esteira, Gadotti (2003, p. 25) deixa claro que para uma educação de futuro o professor deverá assumir uma "postura mais relacional [...] dialógica, cultural, contextual e comunitária", estando mais próximo dos "aspectos éticos, coletivos, comunicativos, comportamentais, emocionais [...] todos eles necessários para se alcançar uma educação democrática dos futuros cidadãos" (IMBERNÓN, 2000, p. 11).

Seguindo esse mesmo raciocínio, Bertrand (2001) afirma que o fundamental é encontrar um sentido para a vida das pessoas alicerçado na inteligência e na afetividade, tendo reflexos no desempenho social. Contudo, para que isso possa ser posto em prática, serão necessários 
novos saberes, entre os quais, saber planejar, saber pesquisar, saber organizar o currículo, saber conviver - consigo mesmo e com seus alunos.

Marchesi (2006), por sua vez, salienta que a educação deve tratar de manter de forma coordenada e coesa, três grandes objetivos que, na sua visão, são essenciais para uma educação de/do futuro, são eles:

a) despertar o desejo de saber dos alunos - isto é, ampliar os conhecimentos desse aluno;

b) cuidar da sensibilidade e da vida afetiva dos alunos - em muitos casos a preocupação dos professores com o equilíbrio afetivo dos alunos só acontece quando percebem que está perturbando sua dedicação ao estudo. Entretanto, compartilhamos da ideia de Marchesi de que a educação afetiva é uma condição essencial, uma vez que é parte integrante da felicidade humana e, por isso, é preciso estar incluída no projeto educacional das escolas e na ação pedagógica de todos os professores, sem exceção;

c) facilitar o compromisso moral com seus alunos - esse objetivo centra-se na educação moral, que deve ser formulada e vivida nas relações com o outro e deve se consolidar com os princípios que melhor regulam o comportamento humano. A educação moral se apoia no afeto, nas relações socioafetivas e na própria reflexão.

Nesse sentido, uma das formas de se alcançar esses objetivos é pensarmos em uma prática educativa orientada por um viés inclusivo, que vise à promoção de atividades formativas e sociais. Uma prática que (re)construa valores, tais como: responsabilidade, tolerância, respeito ao próximo, acolhimento do diferente, solidariedade como compromisso pessoal e coletivo com a justiça (FERNANDES, 2008).

Pensamos, assim como Gaya (2006), numa escola mais aberta, mais flexível, que busque superar o velho modelo (enciclopédico e intelectualista) alicerçado em bases sólidas do Iluminismo. E, para tanto, 
nós professores, necessitamos transformar em ação o discurso da complexidade. Numa práxis efetiva. Todavia, nesta pedagogia, por natureza complexa, não se pode prescindir de uma visão alargada do conhecimento. Uma visão que ultrapasse as fronteiras do exclusivamente racional (GAYA, 2006, p. 267).

E, para que isso ocorra, é preciso que o professor acredite na mudança, zele por uma coerência total entre suas ideias e suas ações na prática educacional; busque conteúdos e uma metodologia de ensino dinâmica e reflexiva (SCHÖN, 1998). Em outras palavras, uma aprendizagem formativa que proporcione ao seu aluno o desenvolvimento de um ser pensante, autônomo, criativo e crítico.

Para o alcance desse objetivo, o professor fomenta e trabalha com atividades que permitam aos seus alunos vivenciar a satisfação de se sentirem capazes e valorizados. Desse modo, o cuidado que o professor possa ter para com seu aluno no que tange à afetividade contribui - e muito - para o desenvolvimento pessoal, favorecendo o compromisso do aluno com a aprendizagem, diminuindo as possibilidades para o fracasso escolar, proporcionando um importante substrato para o desenvolvimento social, moral e ético.

A Educação, portanto, é promotora e iniciadora de valores. Valores esses tão bem defendidos por Gaya (2006), que ao verificar a necessidade de uma pedagogia mais complexa pede para que nossas escolas incentivem, por exemplo, a criação de corais, bandas de música, grupos de teatro, clubes de ciência, clubes de lazer e esporte, em suma, que nossas escolas e nossa pedagogia incentivem nossos alunos a viverem dentro e fora da escola!

Tal fato nos remete ao compromisso inadiável e irrevogável da Educação que é propiciar ao homem humanizar-se. A esse respeito Roitman (2001, p. 147, grifo nosso) afirma que:

o grande desafio que se nos apresenta e deverá ser enfrentado por todos nós, nesse período de grandes mudanças tecnológicas, com novos 
padrões de comunicação, em uma globalização unificadora das sociedades, em meio a crises, competições, desencontros, quebras de valores e instabilidade, é o de educar sem perder a perspectiva do humano.

Educar é compreender! Compreender primeiramente as pessoas; é lidar bem com seus sentimentos e emoções e com os sentimentos e emoções de seus alunos. Como já dizia Morin (2001), compreender requer empatia, abertura para ouvir e, por que não dizer, sentir na pele o que o outro está vivendo. Dito isso, compartilhamos da ideia de Mosquera (2003) ao afirmar que, para uma educação humanizante, precisamos dar asas ao saber, saber esse tecnológico e científico e, principalmente, dar asas ao ser humano, que é a base para o conhecimento.

\section{Considerações finais à guisa de conclusão}

Estamos vivendo em um período em que a sociedade caracteriza-se pelo pluralismo de ideias, pela complexidade das práticas sociais e dos saberes nela e com ela produzidos. Por isso, é importante que nós professores nos apercebamos de que é preciso haver a mudança do olhar e do sentir; é preciso a valorização do ser humano! Num ensino que se pretende comprometido para outro mundo possível, o conhecimento é o bem mais significativo e valioso que podemos possuir.

Esse conhecimento deverá ser democratizado e solidário, a fim de proporcionar ao ser humano maiores possibilidades de uma vida vivida com dignidade e justiça. $\mathrm{O}$ conhecimento em seus modos de produção na sua totalidade como totalidades em movimentos de totalização (SANTOS, 1996), está permanentemente em processo como produção histórica situada na relação tempo-espaço-contingências.

Nessa compreensão, um conhecimento é produzido nessa relação com a tecitura de diferentes tipos de saberes. E isso só será possível se acreditarmos em um sujeito ativo, que seja capaz de decidir as suas possibilidades, capaz de planejar e responder criativamente a situações 
novas; que seja capaz de entender o outro com quem convive e o mundo em que vive.

Em uma tentativa de síntese provisória, podemos dizer que para uma educação de presente-futuro ético e de humanas gentes, torna-se necessário investir no desenvolvimento de ser humano em sua inteireza (FREIRE, 1996); em sua multidimensionalidade pessoal, cultural e, também, profissional, em que a humanidade de suas ações tenha a capacidade de promover a solidariedade, a prática social cidadã.

Por outras palavras, assumir-se protagonista de sua própria vida na relação com os outros, fazendo-se perceber o ser humano como sujeito e não como um simples objeto, consciente de seus limites e possibilidades nos movimentos de sua totalidade e complexidade (física, moral, estética e espiritual).

\section{Referências}

ARROYO, M. G. Ofício de mestre. Petrópolis: Vozes, 2000.

BENTO, J. O. Desporto para crianças e jovens: das causas e dos fins. In: GAYA, A.; MARQUES, A.; TANI, G. (Org.). Desporto para crianças e jovens: razões e finalidades. Porto Alegre: UFRGS, 2004. p. 21-56.

BERTRAND, Y. Teoria personalista. In: BERTRAND, Y. Teorias contemporâneas da educação. Lisboa: Instituto Piaget, 2001. p. 41-64.

CHAUÍ, M. Convite à filosofia. São Paulo: Ática, 1998.

COLOM, A. J. A (des)construção do conhecimento pedagógico: novas perspectivas para a educação. Porto Alegre: Artmed, 2004.

COSTA, W. M. M. Pedagogia e complexidade: uma articulação necessária. In: CARVALHO, E. de A.; MENDONÇA, T. (Org.). Ensaios de complexidade 2. Porto Alegre: Sulina, 2003. p. 266-275.

DESCARTES, R. Discurso do método. Lisboa: Guimarães, 1997. 
FERNANDES, C. Sala de aula universitária - ruptura, memória educativa, territorialidade: o desafio da construção pedagógica do conhecimento. 1999. Tese de Doutorado (Doutorado em Educação) - Universidade Federal do Rio Grande do Sul, Porto Alegre, 1999.

FERNANDES, C. Docência universitária e os desafios da formação pedagógica. Interface - Comunicação, Saúde, Educação, São Paulo, n. 9, p. 177-182, 2001. Espaço aberto.

FERNANDES, C. Prática pedagógica. In: MOROSINI, M. C. et al. Enciclopédia de Pedagogia Universitária. Porto Alegre: FAPERGS/RIES, 2003. p. 229-239.

FERNANDES, C. À procura da senha da vida - de-senha a aula dialógica? In: VEIGA, I. Aula: gênese, dimensões, princípios e práticas. Campinas: Papirus, 2008. p. 145-165.

FLORENTINO, J. A. A. Linearidade, complexidade e sistemas. In: RODRIGUES, L. P. (Org.). Sociedade, conhecimento e interdisciplinaridade: abordagens contemporâneas. Passo Fundo: Ed. da UPF, 2007. p. 47-94.

FREIRE, P.; SHOR, I. Medo e ousadia: o cotidiano do professor. Rio de Janeiro: Paz e Terra, 1987.

FREIRE, P. Pedagogia da autonomia: saberes necessários à prática educativa. Rio de Janeiro: Paz e Terra, 1996.

GADOTTI, M. Boniteza de um sonho: ensinar-e-aprender com sentido. Novo Hamburgo: Feevale, 2003.

GAYA, A. A reinvenção dos corpos: por uma pedagogia da complexidade. Sociologias, Porto Alegre, v. 8, n. 15, p. 250-272, jan./jun. 2006.

IMBERNÓN, F. Formação docente e profissional: formar-se para a mudança e a incerteza. São Paulo: Cortez, 2000.

LIMA, G. Sociologia na complexidade. Sociologias, Porto Alegre, v. 8, n. 15, p. 136-181, jan./jun. 2006. 
MARCHESI, A. O que será de nós, os maus alunos? Porto Alegre: Artmed, 2006.

MARIOTTI, H. As paixões do ego: complexidade, política e solidariedade. São Paulo: Palas Athena, 2000.

MOREIRA, W.; PELLEGRINOTTI, I. L.; BORIN, J. P. Formação profissional em esporte: a complexidade e a performance humana. In: TANI, G.; BENTO, J. O.; PEtersen, R. D. de S. (Org.). Pedagogia do desporto. Rio de Janeiro: Guanabara Koogan, 2006. p. 185-192.

MORIN, E.; LE MOIGNE, J. L. A inteligência da complexidade. São Paulo: Peirópolis, 2000.

MORIN, E. A cabeça bem-feita. Rio de Janeiro: Bertrand Brasil, 2001.

MOSQUERA, J. J. M. A educação no terceiro milênio. Revista Educação PUCRS, Especial, v. 26, p. 43-58, 2003.

NEWTON, I. Princípios matemáticos. In: NEWTON, I. Os pensadores. Rio de Janeiro: Abril Cultural, 1974. p. 7-28.

ROITMAN, R. A dimensão político-pedagógica da Educação Física. In: VARGAS, A. L. Desporto e tramas sociais. Rio de Janeiro: Sprint, 2001. p. 145-153.

SANTOS, A. Complexidade e transdisciplinaridade em educação: cinco princípios para resgatar o elo perdido. Revista Brasileira de Educação, v. 13, n. 37, p. 71-84, 2008.

SANTOS, M. A natureza do espaço: técnica e tempo - razão e emoção. São Paulo: Hucitec, 1996.

SCHÖN, D. Educando o profissional reflexivo. Porto Alegre: Artmed, 1998.

SOUSA SANTOS, B. Um discurso sobre as ciências. Porto: Edições Afrontamento, 1987. 
TROCMÉ-FABRE, H. Reaprender a complexidade. In: CARVALHO, E. de A.; MENDONÇA, T. (Org.). Ensaios de complexidade 2. Porto Alegre: Sulina, 2003. p. 133-139.

VASCONCELLOS, M. J. E. Pensamento sistêmico: o novo paradigma da ciência. São Paulo: Papirus, 2005.

VIEIRA PINTO, A. Ciência e existência: problemas filosóficos da pesquisa científica. Rio de Janeiro: Paz e Terra, 1969.

Recebido: 10/04/2009

Received: 04/10/2009

Aprovado: 12/06/2009

Approved: 06/12/2009 